\title{
A retrospective survey of the last 3 months of life in patients carrying glioblastoma: Clinical treatments and profiles
}

\author{
ROMAIN RIVOIRARD ${ }^{1}$, ALEXIS VALLARD ${ }^{2}$, CLAIRE BOUTET $^{3}$, \\ ALEXANDER TUAN FALK ${ }^{4}$, CLEMENCE GARIN $^{2}$, ANISSA ADJABI $^{2}$, DELPHINE HOARAU $^{2}$, \\ FABIEN FOREST ${ }^{5}$, MARIE-JEANNETTE FOTSO ${ }^{6}$, CHLOE RANCOULE $^{2}$ and NICOLAS MAGNÉ ${ }^{2}$
}

\begin{abstract}
Departments of ${ }^{1}$ Medical Oncology and ${ }^{2}$ Radiotherapy, Lucien Neuwirth Institute of Cancerology; ${ }^{3}$ Department of Morphological and Functional Imaging, St. Etienne North Hospital, 42270 Saint Priest en Jarez; ${ }^{4}$ Departement of Radiation Oncology,

Centre Antoine Lacassagne, 06100 Nice; ${ }^{5}$ Anatomopathology Laboratory; ${ }^{6}$ Department

of Neurosurgery, CHU Saint Etienne, 42270 Saint Priest en Jarez, France
\end{abstract}

Received April 25, 2017; Accepted September 28, 2017

DOI: $10.3892 / \mathrm{mco} .2017 .1479$

\begin{abstract}
Glioblastoma is one of the most common types of primary brain tumor. In situations of local recurrence, physicians can suggest either specific palliative anticancer treatments (SPAT; surgery, chemotherapy, radiotherapy) or best supportive care (BSC). The objective of the present study was to identify clinical factors that may have influenced the continuation or cessation of SPAT during the final 3 months of life in patients with glioblastoma. In the present retrospective single-center study, all records of patients treated for glioblastoma, who succumbed to the disease between June 2006 and February 2014, were assessed. All selected patients were divided into two groups, according to treatments received during the last 3 months of life: The SPAT and BSC groups. A total of 148 patients were included: 81 patients in the SPAT group (group A) and 67 patients in the BSC group (group B). A performance status equal to 0 was observed for $17.3 \%$ of patients in group A vs. $6 \%$ in group B. Following progression, chemotherapy was administered in $39.5 \%$ of cases in group A vs. $20.9 \%$ of cases in group B $(\mathrm{P}=0.0149)$. The mean number of lines of chemotherapy administered in group A was equal to $1.44 \pm 0.77$ as compared with $1.06 \pm 0.67$ in group $\mathrm{B}(\mathrm{P}=0.0017)$. SPAT are utilized frequently among patients approaching mortality due to a glioblastoma. Certain factors, including the utilization of novel chemotherapy after the first progression or number of lines of chemotherapy previously administered, may have influenced physicians' decisions whether to continue with the SPAT or not.
\end{abstract}

Correspondence to: Professor Nicolas Magné, Department of Radiotherapy, Lucien Neuwirth Institute of Cancerology, 108bis Avenue Albert Raimond, 42270 Saint Priest en Jarez, France E-mail: nicolas.magne@icloire.fr

Key words: glioblastoma, palliative treatments, supportive care, surgery, chemotherapy, radiotherapy

\section{Introduction}

Among all primitive types of brain tumor, glioblastoma remains one of the most common, with an incidence of 3.2/100,000 individuals annually (1). With increasing life expectancy in Western countries, a steady increase in the incidence of this cancer has occurred in recent decades $(2,3)$; the incidence in people $>65$ has doubled in 30 years (from 5.7/100,000 inhabitants between 1974 and 1981 to 10.6 per 100,000 between 1989 and 1999) (4). Glioblastoma has a very poor prognosis with a median survival of 14.6 months in patients treated with surgery, radiotherapy and concomitant chemotherapy (5). Due to the aggressiveness of this tumor, multidisciplinary care (neurosurgeon, radiotherapist, medical oncologist, supportive care) remains absolutely necessary, and is initiated rapidly and continued until a late stage of the disease. Indeed, in a situation of local recurrence and when the situation permits, several specific treatments may be proposed: Reoperation $(6,7)$, with or without implants of carmustine, different protocols of chemotherapy (mono or dual therapy) using or not temozolomide $(8-12)$, targeted therapies including bevacizumab $(13,14)$ and re-irradiation in rare selected cases (15-17). These options can be considered as specific palliative anticancer treatments (SPAT). By contrast, when the clinical profile does not allow the patient to tolerate these treatment types, only the pursuit of a treatment based on best supportive care (BSC) remains possible (corticosteroids, anti-edematous treatment, treatment of nausea, pain and undernutrition). It is difficult to specifically detail the clinical factors that may impact the medical decision to continue or not with SPAT in patients with glioblastoma in terminal phase.

The objective of the present study was to analyze the therapeutic management of patients with glioblastoma during their last 3 months of life and to identify clinical criteria that may influence the decision of stopping SPAT at the end of life.

\section{Patients and methods}

Population. All patients with a glioblastoma and who succumbed to mortality in the medical oncology unit or at 
home between June 30th 2006 and February 27th 2014 were taken into account in this retrospective mono-centric study. Medical records from radiotherapy and medical oncology departments of Lucien Neuwirth Cancerology Institute were analyzed, with glioblastoma histologically confirmed. When certain data were missing, the patient's general physician or family were contacted for more data. The date of death was obtained by registers of the units, which corresponded to the date of the death certificate signed by the physician. Demographic data were age, gender, performance status (PS), recursive partitioning analysis (RPA) score and occurrence of symptoms such as motor and/or sensitive deficit and cognitive dysfunction at the time of diagnosis. For each patient, the presence or absence of cognitive disorder was assessed by using the mini-mental state examination (18). This test was performed in the month following diagnosis. Pathological thresholds were variable depending on the patient's socio-cultural level. All treatment options (SPAT or BSC) were previously presented to patients in consultation, delivering clear, fair and adequate information on the risk/benefit ratio. Patient preferences were taken into consideration. All decisions were then confirmed following a multidisciplinary meeting. The study design was approved by the local ethics committee.

Cancer and treatment data. Cancer-associated data were as follows: Date of diagnosis, type of surgery (biopsy or operation), tumor location and notion of reoperation. O6-methylguanine-DNA-methyltransferase (MGMT) status was not available for all patients and was therefore not considered in the present study. Anticancer treatments administered during the last 3 months of life were divided into two groups: i) the SPAT group, which included surgery, chemotherapy and radiotherapy; and ii) the BSC group (symptomatic treatment).

Patients receiving SPAT were assessed every 3 months through a neurological clinical examination and cerebral magnetic resonance imaging with gadolinium injection [sequences T1-, T2 and fluid attenuation inversion recovery (FLAIR)]. Biological parameters [platelets, polynuclear neutrophils, hemoglobin, creatinine and the modification of the diet in renal disease (MDRD) calculation of creatinine clearance] were controlled by blood samples, 24-48 h prior to each cycle of chemotherapy.

Statistical analysis. The mean, standard deviations, medians and ranges were used as descriptive statistics. The present study analyzed the type of treatment administered during the last 3 months of life, but also the initial treatment received for patients. For each group, overall survival (OS) was calculated from the date of histological diagnosis and from the time of recurrence. Progression-free survival (PFS), defined as the time elapsed between treatment initiation and tumor progression or mortality from any cause, was also calculated. The association of type of treatment received during the last 3 months of life (SPAT or BSC) with a patient's initial characteristics and the specific treatments at initial management were assessed by $\chi^{2}$ test, Wilcoxon rank sum test and t-test, as appropriate $(\mathrm{P}=0.05)$. Kolmogorov-Smirnov test was used for testing normality of each variable: $\mathrm{P}<0.05$ was considered to indicate a statistically significant difference.

\section{Results}

Patient characteristics. For the present study, 148 patients with glioblastoma who succumbed to mortality between June 30th 2006 and February 27th 2014 were included. Among them, 81 patients ( $54.7 \%$ of cases) had received a SPAT during their final 3 months of life, while 67 patients (45.3\% of cases) had received BSC. The initial PS equal to 0 was observed in 14 patients (17.3\% of cases) in the SPAT group and in 4 patients ( $6 \%$ of cases) in the $\mathrm{BSC}$ group $(\mathrm{P}=0.051)$. RPA score was equal to $\mathrm{V}$ in 34 patients $(50.7 \%$ of cases) in the BSC group vs. 27 patients (33.3\% of cases) in the SPAT group $(\mathrm{P}=0.19)$. Finally, a recent history of epilepsy at diagnosis was observed in 26 patients (38.8\% of cases) in the BSC group compared with 20 patients (24.7\% of cases) in the SPAT group $(\mathrm{P}=0.065$; Table I).

Tumor locations. In the SPAT group, the predominant tumor locations were the frontal lobe $(22.2 \%$ of cases) and the temporal lobe (16\% of cases). For the BSC group, the temporal lobe and the frontal lobe were the most common locations (29.9 and $13.4 \%$ of cases, respectively) (Table II). All patients had a diagnosis of primary glioblastoma.

Specific treatments for the initial management. During initial surgery, complete resection was obtained in $34.6 \%$ of cases in the SPAT group and $20.9 \%$ of cases in BSC group. Patients in the SPAT group have more often received adjuvant chemotherapy with temozolomide (79\% of cases in the SPAT group vs. $61.2 \%$ of cases in the BSC group, $\mathrm{P}=0.0175$ ). At progression, a second-line chemotherapy was more often performed in the SPAT group (39.5\% of cases) compared with in the group BSC (20.9\% of cases, $\mathrm{P}=0.0149)$. The mean number of lines of chemotherapy was higher in SPAT group compared with the BSC group: $1.44(0.77)$ vs. $1.06(0.67)$, respectively ( $\mathrm{P}=0.0017$; Table III). Details of specific treatments received during the last 3 months of life (SPAT group). The majority of patients in the SPAT group received chemotherapy during their last 3 months of life: $74 / 81$ patients or $91.3 \%$ of cases. The most frequently administered chemotherapies were temozolomide (45/81 patients, $55.5 \%$ of cases) and irinotecan, associated with bevacizumab (23/81 patients, $28.4 \%$ of cases, Table IV).

Survival data. The mean OS, calculated from histological diagnosis, were equal to 13.05 months (standard deviation, 9.58) in the SPAT group and equal to 13.04 (standard deviation, $9.14)$ in the BSC group $(\mathrm{P}=0.86)$. From the time of recurrence, the median OS was equal to 2 months (0-28 months) in the BSC group vs. 2 months (0-22 months) in the SPAT group. The mean PFS was equal to 8.99 months (standard deviation, 6.71) in the SPAT group and 7.76 months (standard deviation, 4.85) in the BSC group $(\mathrm{P}=0.40$, Table $\mathrm{V})$.

\section{Discussion}

At first, the SPAT term may appear ambiguous. In a context of currently incurable cancer, the present study considered the included patients as receiving palliative treatment whose purpose was not to complete cure, but to obtain tumor control. The notable result that emerges from the present study is that 
Table I. Patient characteristics $(n=148)$.

\begin{tabular}{|c|c|c|c|}
\hline Characteristic & SPAT group, n (\%) & BSC group, n (\%) & P-value \\
\hline No. patients & $81(54.7)$ & $67(45.3)$ & \\
\hline Mean age at diagnosis, years (SD) & $62(11.8)$ & $64(10.3)$ & $0.32^{\mathrm{a}}$ \\
\hline Mean age at death, years (SD) & $63(11.6)$ & $65(10.2)$ & $0.28^{\mathrm{a}}$ \\
\hline Gender & & & $0.95^{\mathrm{b}}$ \\
\hline Male & $50(61.7)$ & $41(61.2)$ & \\
\hline Female & $31(38.3)$ & $26(38.8)$ & \\
\hline PS at diagnosis & & & $0.051^{\mathrm{b}}$ \\
\hline 0 & $14(17.3)$ & $4(6.0)$ & \\
\hline 1 & $44(54.3)$ & $35(52.2)$ & \\
\hline$\geq 2$ & $23(28.4)$ & $28(41.8)$ & \\
\hline RPA score at diagnosis & & & $0.19^{\mathrm{b}}$ \\
\hline III & $6(7.4)$ & $3(4.5)$ & \\
\hline IV & $37(45.7)$ & $24(35.8)$ & \\
\hline $\mathrm{V}$ & $27(33.3)$ & $34(50.7)$ & \\
\hline VI & $11(13.6)$ & $6(9.0)$ & \\
\hline \multicolumn{4}{|l|}{ Intracranial hypertension at diagnosis } \\
\hline Yes & $29(35.8)$ & $16(23.9)$ & \\
\hline No & $52(64.2)$ & $51(76.1)$ & \\
\hline Epilepsy at diagnosis & & & $0.065^{\mathrm{b}}$ \\
\hline Yes & $20(24.7)$ & $26(38.8)$ & \\
\hline No & $61(75.3)$ & $41(61.2)$ & \\
\hline Sensory/motor deficit at diagnosis & & & $0.93^{\mathrm{b}}$ \\
\hline Yes & $49(60.5)$ & $41(61.2)$ & \\
\hline No & $32(39.5)$ & $26(38.8)$ & \\
\hline Cognitive disorders at diagnosis & & & $0.27^{b}$ \\
\hline Yes & $41(50.6)$ & $40(59.7)$ & \\
\hline No & $40(49.4)$ & $27(40.3)$ & \\
\hline
\end{tabular}

${ }^{a}$ Wilcoxon rank sum test; ${ }^{b} \chi^{2}$ test. SPAT, specific palliative anticancer treatments; BSC, best supportive care; PS, performance status; SD, standard deviation.

Table II. Tumor locations $(\mathrm{n}=148)$.

\begin{tabular}{lcc}
\hline Location & $\begin{array}{c}\text { SPAT group, } \\
\mathrm{n}(\%)\end{array}$ & $\begin{array}{c}\text { BSC group, } \\
\mathrm{n}(\%)\end{array}$ \\
\hline Temporal lobe & $13(16)$ & $20(29.9)$ \\
Frontal lobe & $18(22.2)$ & $9(13.4)$ \\
Parietal lobe & $8(10)$ & $9(13.4)$ \\
Parieto-occipital & $12(14.8)$ & $5(7.5)$ \\
Fronto-temporal & $5(6.2)$ & $8(11.9)$ \\
Multifocal & $6(7.4)$ & $5(7.5)$ \\
Fronto-parietal & $6(7.4)$ & $2(3)$ \\
Other locations & $13(16)$ & $9(13.4)$
\end{tabular}

SPAT, specific palliative anticancer treatments; BSC, best supportive care.

more than half of the analyzed patients who exhibited glioblastoma (54.7\% of cases) received SPAT during last 3 months of life. This rate appears particularly high. In the previous study by Viel et al (19), the rate of patients receiving SPAT during the last 3 months of their life was equal to $83.2 \%$ of the analyzed cases (total no., 167 patients). Among the 139 patients treated with SPAT, the most commonly diagnosed cancer types in the initial management were breast cancer ( $16.6 \%$ of cases) and head and neck cancer (14.5\% of cases). The present study also demonstrated that patients who received a SPAT (Group A) were generally younger compared with those who received BSC (Group B). The median age at diagnosis was 58 years (21-87 years) in Group A vs. 69 years (27-87 years) in group B. Patients in group A had also received more previous lines of chemotherapy compared with in Group B; on average, 1.96 vs. 0.39 , respectively. In conclusion, the authors of the study suggested that these factors must be considered (age at diagnosis and number of previous lines of chemotherapy) in the decision-making for cancer patients in the terminal phase. In the SV2 study, it was observed that one of these two factors was also taken into account in the final decision of management of patients with glioblastoma: The mean number of lines 
Table III. Specific treatments for the initial management $(n=148)$.

\begin{tabular}{|c|c|c|c|}
\hline Treatment & $\begin{array}{l}\text { SPAT group } \\
(\mathrm{n}=81)(\%)\end{array}$ & $\begin{array}{l}\text { BSC group } \\
(n=67)(\%)\end{array}$ & P-value \\
\hline Type of initial surgery & & & $0.19^{\mathrm{a}}$ \\
\hline Complete resection & $28(34.6)$ & $14(20.9)$ & \\
\hline Partial resection & $21(25.9)$ & $21(31.3)$ & \\
\hline Stereotactic biopsy & $32(39.5)$ & $32(47.8)$ & \\
\hline Brain radiotherapy & & & $0.34^{\mathrm{a}}$ \\
\hline Yes & $76(94.0)$ & $60(89.5)$ & \\
\hline No & $5(6.0)$ & $7(10.5)$ & \\
\hline Concomitant TMZ & & & $0.16^{\mathrm{a}}$ \\
\hline Yes & $72(88.9)$ & $54(80.6)$ & \\
\hline No & $9(11.1)$ & $13(19.4)$ & \\
\hline Adjuvant TMZ & & & $0.0175^{\mathrm{a}}$ \\
\hline Yes & $64(79.0)$ & $41(61.2)$ & \\
\hline No & $17(21.0)$ & $26(38.8)$ & \\
\hline Mean number of cycles of adjuvant TMZ (SD) & $7(6)$ & $6.49(4.78)$ & $0.59^{\mathrm{b}}$ \\
\hline Chemotherapy at progression & & & $0.0149^{\mathrm{a}}$ \\
\hline Yes & $32(39.5)$ & $49(60.5)$ & \\
\hline No & $14(20.9)$ & $53(79.1)$ & \\
\hline Mean number of lines of chemotherapy (SD) & $1.44(0.77)$ & $1.06(0.67)$ & $\mathbf{0 . 0 0 1 7} 7^{\mathrm{c}}$ \\
\hline
\end{tabular}

Table IV. Details of last specific palliative anticancer treatment performed during the last 3 months of life $(n=81)$.

\begin{tabular}{lc}
\hline Type of treatment & $\mathrm{n}(\%)$ \\
\hline Chemotherapy & $74(91.3)$ \\
Temozolomide & $45(55.5)$ \\
Irinotecan-BVZ & $23(28.4)$ \\
Fotemustine & $3(3.7)$ \\
PCV & $2(2.5)$ \\
Implant of carmustine & $1(1.2)$ \\
Radiotherapy & $17(21.0)$ \\
Surgery & $5(6.2)$ \\
\hline
\end{tabular}

BVZ, bevacizumab; PCV, procarbazine-CCNU-vincristine.

of chemotherapy was higher in the SPAT group compared with in the BSC group: 1.44 (standard deviation, 0.77) against 1.06 (standard deviation, 0.67), respectively $(\mathrm{P}=0.0017)$. However, the mean age at diagnosis was almost similar between both groups; 62 years (standard deviation, 11.8) in the SPAT group vs. 64 years (standard deviation, 10.3) in group BSC $(\mathrm{P}=0.32)$.

Regarding the type of initial surgery, a higher percentage of patients submitted to biopsy alone compared with clinical trials: 64 patients or $43.2 \%$ of cases in SV2 study vs. 93 patients or $16.2 \%$ of cases in the study of Stupp et al (5).
Table V. Survival data in specific palliative anticancer treatment group and in BSC group.

\begin{tabular}{lccc}
\hline Criteria & $\begin{array}{c}\text { SPAT } \\
\text { group (\%) }\end{array}$ & $\begin{array}{c}\text { BSC } \\
\text { group (\%) }\end{array}$ & P-value \\
\hline PFS, months & & & $7.76(4.85)$ \\
6 month PFS rate & 61.7 & 52.2 & \\
9 month PFS rate & 35.8 & 31.3 & \\
12 month PFS rate & 27.1 & 14.9 & \\
Median PFS (range) & $7.8(1-38)$ & $7(1-23)$ & \\
Mean PFS (SD) & $8.99(6.71)$ & $7.76(4.85)$ & \\
OS, months & & & \\
6 month OS rate & 64.2 & $556^{\mathrm{a}}$ \\
9 month OS rate & 45.7 & 46.2 & \\
12 month OS rate & 22.2 & 20.9 & \\
Median OS (range) & $11(1-50)$ & $11(1-47)$ & \\
Mean OS (SD) & $13.05(9.58)$ & $13.04(9.14)$ & \\
\hline
\end{tabular}

${ }^{a}$ Wilcoxon rank sum test. SPAT, specific palliative anticancer treatments; BSC, best supportive care; SD, standard deviation; PFS, progression-free survival; OS, overall survival.

This may be explained by a high proportion of patients with an altered health condition at diagnosis ( $\mathrm{PS} \geq 2$ for 51 patients or $34.4 \%$ of SV2 in the study vs. 73 patients or $12.7 \%$ of cases 
in the previous study) (5) and with an unfavorable RPA score (score of V or VI for 78 patients or $52.7 \%$ of cases in the SV2 study). Concerning chemotherapy in the BSC group, a high percentage of patients did not receive adjuvant temozolomide ( 38.8 vs. $21.0 \%$ of cases in the SPAT group, $\mathrm{P}=0.0175$ ). The reasons for discontinuation of the STUPP protocol (5) in the BSC group were predominantly death (5 patients), $\mathrm{PS}=4$ following completion of radiotherapy ( 9 patients) and persistent grade 4 thrombocytopenia (4 patients). By analyzing the results of the SV2 study, one other criterion may have been involved in the decision whether to continue or not SPAT in patients with glioblastoma and near the end of their life: After a first progression, the percentage of treatment with a second line chemotherapy was higher in the SPAT group (39.5 vs. $20.9 \%$ of cases in BSC group, $\mathrm{P}=0.0149$ ).

The second result, which has to be emphasized in the SV2 study, is that no difference for OS was observed between the SPAT group and the BSC group; the mean OS was equal to 13.05 (standard deviation, 9.58) months in the SPAT group and 13.04 months (standard deviation, 9.14) in the BSC group $(\mathrm{P}=0.86)$. Additionally, the mean PFS was quite similar between the two groups (8.99 months, standard deviation, 6.71 for the SPAT group vs. 7.76 months, standard deviation, 4.85 for the BSC group, $\mathrm{P}=0.40$ ); therefore, this criterion could not be considered as a major criterion for the decision of SPAT or BSC. These results are the source of questions about the usefulness of SPAT in patients close to mortality and suffering from glioblastoma. Earle et al (20) noted that the treatment of cancer patients near death is becoming increasingly aggressive over time. Between 1993 and 1996, the rate of patients who still received chemotherapy in their last two weeks of life grew from 13.8 to $18.5 \%$, respectively $(\mathrm{P}<0.001)$. A second article by Earle et al (21) focused on the probable overuse of chemotherapy among cancer patients at their end of life. However, it has already been demonstrated that the use of chemotherapy near the end of life is not associated with its ability to produce benefits (22). In fact, patient preference appears to still have a restrained role for the choice to pursue SPAT or not $(23,24)$. Physicians use several arguments to explain the continuation of treatments producing limited benefits to cancer patients near the end of life. For example, these treatments can be considered as a potential hope for the patient, or the development of novel targeted therapies with few side effects allows these treatments to be maintained until the last days of life of the patient. It should also be noted that the discussion with the patient on the cessation of active treatment of cancer and the development of symptomatic and supportive care is an event that is often difficult to approach.

The implementation of supportive care of good quality, with the main objective of patient comfort at end of life, remains indispensable. It should be acknowledged that, to date, bevacizumab failed to obtain approval as second line therapy in Europe, and that no third line has demonstrated any clinical benefit. Therefore, it appears that a substantial number of patients clearly receive a treatment with no demonstration of its usefulness.

In conclusion, SPAT and, in particular, chemotherapy, are used frequently among patients near death and with a glioblastoma. Certain factors, including utilization of novel chemotherapy after the first progression or number of lines of chemotherapy previously administered, may have influenced physicians in the decision as to whether to continue or not the SPAT. Palliative care for these patients with glioblastoma remains essential.

\section{References}

1. Ostrom QT, Gittleman H, Fulop J, Liu M, Blanda R, Kromer C, Wolinsky Y, Kruchko C and Barnholtz-Sloan JS: CBTRUS Statistical Report: Primary brain and central nervous system tumors diagnosed in the united states in 2008-2012. Neuro Oncol 17 (Suppl 4): iv1-iv62, 2015.

2. Zouaoui S, Rigau V, Mathieu-Daudé H, Darlix A, Bessaoud F, Fabbro-Peray P, Bauchet F, Kerr C, Fabbro M, Figarella-Branger D, et al: French brain tumor database: General results on 40,000 cases, main current applications and future prospects. Neurochirurgie 58: 4-13, 2012 (In French).

3. Baldi I, Huchet A, Bauchet L and Loiseau H: Epidemiology of glioblastoma. Neurochirurgie 56: 433-440, 2010 (In French).

4. Chakrabarti I, Cockburn M, Cozen W, Wang YP and Preston-Martin S: A population-based description of glioblastoma multiforme in Los Angeles County, 1974-1999. Cancer 104: 2798-2806, 2005.

5. Stupp R, Mason WP, van den Bent MJ, Weller M, Fisher B, Taphoorn MJ, Belanger K, Brandes AA, Marosi C, Bogdahn U, et al: Radiotherapy plus concomitant and adjuvant temozolomide for glioblastoma. N Engl J Med 352: 987-996, 2005.

6. Hart MG, Grant R, Garside R, Rogers G, Somerville M and Stein K: Chemotherapy wafers for high grade glioma. Cochrane Database Syst Rev 16: CD007294, 2011.

7. Lonjon N, Bauchet L, Duffau H, Fabbro-Peray P, Segnarbieux F, Paquis $\mathrm{P}$ and Lonjon $\mathrm{M}$ : Second surgery for glioblastoma. A 4-year retrospective study conducted in both the Montpellier and Nice Departments of Neurosurgery. A literature review. Neurochirurgie 56: 36-42, 2010.,

8. Addeo R, Caraglia M, De Santi MS, Montella L, Abbruzzese A, Parlato C, Vincenzi B, Carraturo M, Faiola V, Genovese M, et al: A new schedule of fotemustine in temozolomide-pretreated patients with relapsing glioblastoma. J Neurooncol 102: 417-424, 2011.

9. Levin VA, Wara WM, Davis RL, Vestnys P, Resser KJ, Yatsko K, Nutik S, Gutin PH and Wilson CB: Phase III comparison of $\mathrm{BCNU}$ and the combination of procarbazine, CCNU, and vincristine administered after radiotherapy with hydroxyurea for malignant gliomas. J Neurosurg 63: 218-223, 1985.

10. Cloughesy TF, Filka E, Kuhn J, Nelson G, Kabbinavar F, Friedman H, Miller LL and Elfring GL: Two studies evaluating irinotecan treatment for recurrent malignant glioma using an every-3-week regimen. Cancer 97 (9 Suppl): S2381-S2386, 2003.

11. Prados MD, Lamborn K, Yung WK, Jaeckle K, Robins HI, Mehta M, Fine HA, Wen PY, Cloughesy T, Chang S, et al: A phase 2 trial of irinotecan (CPT-11) in patients with recurrent malignant glioma: A north american brain tumor consortium study. Neuro-Oncol 8: 189-193, 2006.

12. Quinn JA, Jiang SX, Reardon DA, Desjardins A, Vredenburgh JJ, Rich JN, Gururangan S, Friedman AH, Bigner DD, Sampson JH, et al: Phase II trial of temozolomide plus o6-benzylguanine in adults with recurrent, temozolomide-resistant malignant glioma. J Clin Oncol 27: 1262-1267, 2009.

13. Friedman HS, Prados MD, Wen PY, Mikkelsen T, Schiff D, Abrey LE, Yung WK, Paleologos N, Nicholas MK, Jensen R, et al: Bevacizumab alone and in combination with irinotecan in recurrent glioblastoma. J Clin Oncol 27: 4733-4740, 2009.

14. Vredenburgh JJ, Desjardins A, Herndon JE II, Marcello J, Reardon DA, Quinn JA, Rich JN, Sathornsumetee S, Gururangan S, Sampson J, et al: Bevacizumab plus irinotecan in recurrent glioblastoma multiforme. J Clin Oncol 25: 4722-4729, 2007.

15. Combs SE, Thilmann C, Edler L, Debus J and Schulz-Ertner D: Efficacy of fractionated stereotactic reirradiation in recurrent gliomas: Long-term results in 172 patients treated in a single institution. J Clin Oncol 23: 8863-8869, 2005.

16. Fogh SE, Andrews DW, Glass J, Curran W, Glass C, Champ C, Evans JJ, Hyslop T, Pequignot E, Downes B, et al: Hypofractionated stereotactic radiation therapy: An effective therapy for recurrent high-grade gliomas. J Clin Oncol 28: 3048-3053, 2010. 
17. Patel M, Siddiqui F, Jin JY, Mikkelsen T, Rosenblum M, Movsas B and Ryu S: Salvage reirradiation for recurrent glioblastoma with radiosurgery: Radiographic response and improved survival. J Neurooncol 92: 185-191, 2009.

18. Derouesne C, Poitreneau J, Hugonot L, Kalafat M, Dubois B and Laurent B: Mini-Mental State Examination: A useful method for the evaluation of the cognitive status of patients by the clinician. Presse Med 28: 1141-1148, 1999.

19. Viel E, Chaigneau L,Fanton E, Kalbacher E, Thiery-Vuillemnin A, Villanueva C, Dobi E, Curtit E, Almotlak H, Aubry R and Pivot X: Specific anticancer treatments in the last 3 months of life: A French experience. Support Care Cancer 21: 405-412, 2013.

20. Earle CC, Neville BA, Landrum MB, Ayanian JZ, Block SD and Weeks JC: Trends in the aggressiveness of cancer care near the end of life. J Clin Oncol 22: 315-321, 2004.
21. Earle CC, Landrum MB, Souza JM, Neville BA, Weeks JC and Ayanian JZ: Aggressiveness of cancer care near the end of life: Is it a quality-of-care issue? J Clin Oncol 26: 3860-3866, 2008.

22. Emanuel EJ, Young-Xu Y, Levinsky NG, Gazelle G, Saynina O and Ash AS: Chemotherapy use among medicare beneficiaries at the end of life. Ann Intern Med 138: 639-643, 2003.

23. Barnato AE, Herndon MB, Anthony DL, Gallagher PM, Skinner JS, Bynum JP and Fisher ES: Are regional variations in end-of-life care intensity explained by patient preferences? A Study of the US Medicare Population. Med Care 45: 386-393, 2007.

24. Voogt E, van der Heide A, Rietjens JA, van Leeuwen AF, Visser AP, van der Rijt CC and van der Maas PJ: Attitudes of patients with incurable cancer toward medical treatment in the last phase of life. J Clin Oncol 23: 2012-2019, 2005. 